\title{
Emotional coping among communities affected by wildlife-caused damage in north-east India: opportunities for building tolerance and improving conservation outcomes
}

Mayuri Gogoi

\begin{abstract}
Human-wildlife conflict has been the focus of much research, and incidents of damage caused by wildlife to communities, as well as damage inflicted on wildlife by people, have been studied extensively to determine causes, conditions, impacts and mitigation strategies. However, few studies have explored the coping strategies employed by communities to deal with these stressful events. Understanding coping is important, as effective coping builds tolerance towards wildlife, whereas poor coping erodes tolerance and thus jeopardizes conservation. Interviews conducted with people who had experienced damage caused by wild elephants Elephas maximus in eight villages of Assam, in north-east India, found that the stress experienced by the communities as a result of the damage was eased by their religious beliefs associated with elephants, and their feelings of empathy towards these animals. Belief in the elephant as God and as avenger of wrongdoing further strengthened people's coping capacity. These findings have positive implications for elephant conservation, showing that people's tolerance towards marauding elephants can be based on religious beliefs rather than compensation for losses.
\end{abstract}

Keywords Assam, elephants, emotion-focused coping, human-wildlife conflict, India, qualitative, religion, tolerance

\section{Introduction}

T $T$ ildlife conservation faces significant challenges, with the ongoing and rapid depletion of wild areas and increasing frequency of violent encounters between people and wild animals. However, researchers have cautioned against the use of terms such as human-animal and human-wildlife conflict, as most of these conflict situations have an underlying human-human dimension (Redpath et al., 2015), and technocratic strategies to address them from a strict biological and ecological perspective have

MAYurI Gogor Department of Social Work, University of Delhi, New Delhi, India. E-mail mayuri.gogoi@gmail.com

Received 11 February 2017. Revision requested 3 April 2017.

Accepted 25 July 2017. First published online 21 January 2018. thus far failed to generate favourable outcomes. It is imperative, therefore, to adopt approaches based on scientific understanding of human dimensions of wildlife management that incorporate what people think and do about wildlife, and why, and to utilize these insights to inform policies and processes of wildlife management (Decker \& Lipscomb, 1991; Decker \& Chase, 1997). Furthermore, it is advocated that these approaches be locally focused and specific to species and situations (Fisher, 2016).

One such approach could be to understand how people cope with damage caused by wildlife, and which coping strategies work. Coping has been defined as 'constantly changing cognitive and behavioural efforts to manage specific external and/or internal demands that are appraised as taxing or exceeding the resources of the person' (Lazarus \& Folkman, 1984, p. 141). In coping, while trying to deal with stressful demands, a person makes an effort to 'minimize, avoid, tolerate, change or accept a stressful situation,' as a strategy to reduce stress (Lyon, 2000, p. 11).

Studying coping in communities affected by wildlifecaused damage has wider implications for conservation, as effective coping builds tolerance towards wildlife, whereas poor coping erodes tolerance and engenders negative attitudes towards the conservation of so-called problem animals. Studies of human-animal conflict have focused on the tolerance levels of farmers experiencing conflict, and concluded that tolerance is influenced by factors such as dependence on agriculture, alternative sources of income, size of land-holdings, presence or absence of effective compensation schemes, duration of residence in an area, presence or absence of kinship networks, and a range of ecological factors (Nyerges, 1992; Naughton et al., 1999; Archabald \& Naughton-Treves, 2001; Hill, 2004). Tolerance and coping are correlated but are not synonymous. Tolerance refers to the ability of an individual to bear the losses caused by wildlife, whereas coping refers to the process of managing stress associated with the losses. Thus tolerance can be said to stem from the coping efforts that an individual makes to reduce stress. Lazarus (1966) held that stress consists of three processes: primary appraisal (the process of perceiving a threat to oneself), secondary appraisal (the process of bringing to mind a potential response to the threat), and coping (the process of executing that response), not necessarily in that order. Elaborating further on the ways that people cope with stress, Lazarus \& Folkman (1984) distinguished 
between problem-focused and emotion-focused coping. Problem-focused coping is a proactive measure, 'aimed at problem solving or doing something to alter the source of the stress' (Folkman \& Lazarus, 1980, cited in Carver et al., 1989). In emotion-focused coping, the aim is to diminish or reduce the negative thoughts and feelings associated with distress. Emotion-focused coping is often utilized when a problem is out of control or when the stressor is perceived to be too great to solve.

Employing a qualitative approach, narratives of local people were recorded in eight villages in Assam, in northeast India, which were experiencing damage caused by wild Asian elephants Elephas maximus, often recurrently. The objective was to investigate why and how people tolerated such damage, recording the various emotion-focused coping strategies, such as religion and community ties, that they used to bear the losses caused by wild elephants.

\section{Study area}

The eight study villages are in two administrative districts of Assam: Golaghat (the location of Kaziranga National Park) and Sonitpur (Fig. 1). The study villages in Golaghat are Mohpara, Gorhmur Bortika (hereafter Gorhmur), Mikirchang Bagicha Gaon (hereafter Mikirchang), and Panbari Aadarsha Gaon (hereafter Panbari), and agriculture is the main livelihood activity in all four villages, which are inhabited by a mix of Assamese-speaking Hindus, Santhali-speaking Hindus belonging to the Tea Tribes category, also known as Adivasis (originally from central India, brought by British planters to work in the tea gardens of Assam), and a few Hindu families belonging to the Mishing tribe. The study villages in Sonitpur are No. 1 Jia Gabharu (hereafter Jia Gabharu), Bengenajuli, Bandarhagi Pathar and Rikamari. Agriculture is also the main occupation in these villages, and paddy is the main crop. These villages are inhabited by people belonging to the Assamese Koch community, Adivasis, Nepalis (people originally from Nepal and speaking the Nepali language), Bodos (an ethnically and linguistically distinct tribal community), and Bengali-speaking Muslim families. The Sonai Rupai Wildlife Sanctuary lies to the north of these villages and is enclosed by an electric fence installed by the Forest Department and maintained with the help of WWF.

\section{Methods}

A qualitative research design was employed to capture the experiences and hardships of communities sharing space with wildlife. The study followed a multilevel mixed methods sampling approach (Teddlie \& Tashakkori, 2003), using probability and purposive techniques at various levels to select the final sample of 80 participants (no more than one per household). The majority were male heads of household, but if the head of the household was not available at the time of the interview, their spouse or another adult member of the household was approached. Thirty-four participants in Golaghat and 36 in Sonitpur were male. The high proportion of male participants increases the risk of gender bias in the data; however, patriarchy is a cultural norm in the study area, and men hold important information regarding income, cultivation, crop loss, and compensation.

Data were collected by means of in-depth interviews, in which the researcher was actively engaged in asking, listening, probing and interpreting the narrative accounts of the participants. This was supplemented by observational field notes recorded in the researcher's field diary. The interviews were conducted in Assamese by MG during May 2011January 2012. Interviews were transcribed from audio recordings prior to analysis, and translated into English by MG herself to avoid any loss of information, particularly related to personal disclosure of loss or anxiety (Fraser, 2004). Although care was taken to maintain the accuracy of the conversations, transcription is an interpretative activity (Poland, 1995) and is open to multiple interpretations.

After the data were transcribed a preliminary set of codes were identified based on the transcripts and field notes. Following earlier studies that employed theory-driven analysis rather than using specific analytical tools (Kvale, 2007, pp. 117-118), an analytical framework that integrated various socio-political theories was used to give meaning to the participants' responses.

\section{Results}

Problem-focused and emotion-focused coping strategies were expressed at both the individual and community levels. Active coping strategies implemented by communities included measures such as night guarding of crops, installing early warning systems, and electric fences, which have also been reported elsewhere (Osei-Owusu \& Bakker, 2008; Davies et al., 2011; Hill \& Wallace, 2012). Three types of emotional coping strategies were identified: natural support systems, religion and anthropomorphism.

\section{Natural support systems}

One of the most significant forms of emotional coping used to endure the damage caused by wild elephants was the natural support system available, based on personal associations and relationships developed as part of community living. These include but are not limited to family, friends, neighbours, co-workers and group members (Hirsch, 1980). In natural support systems 'significant others help the individual mobilize his psychological resources and master his 


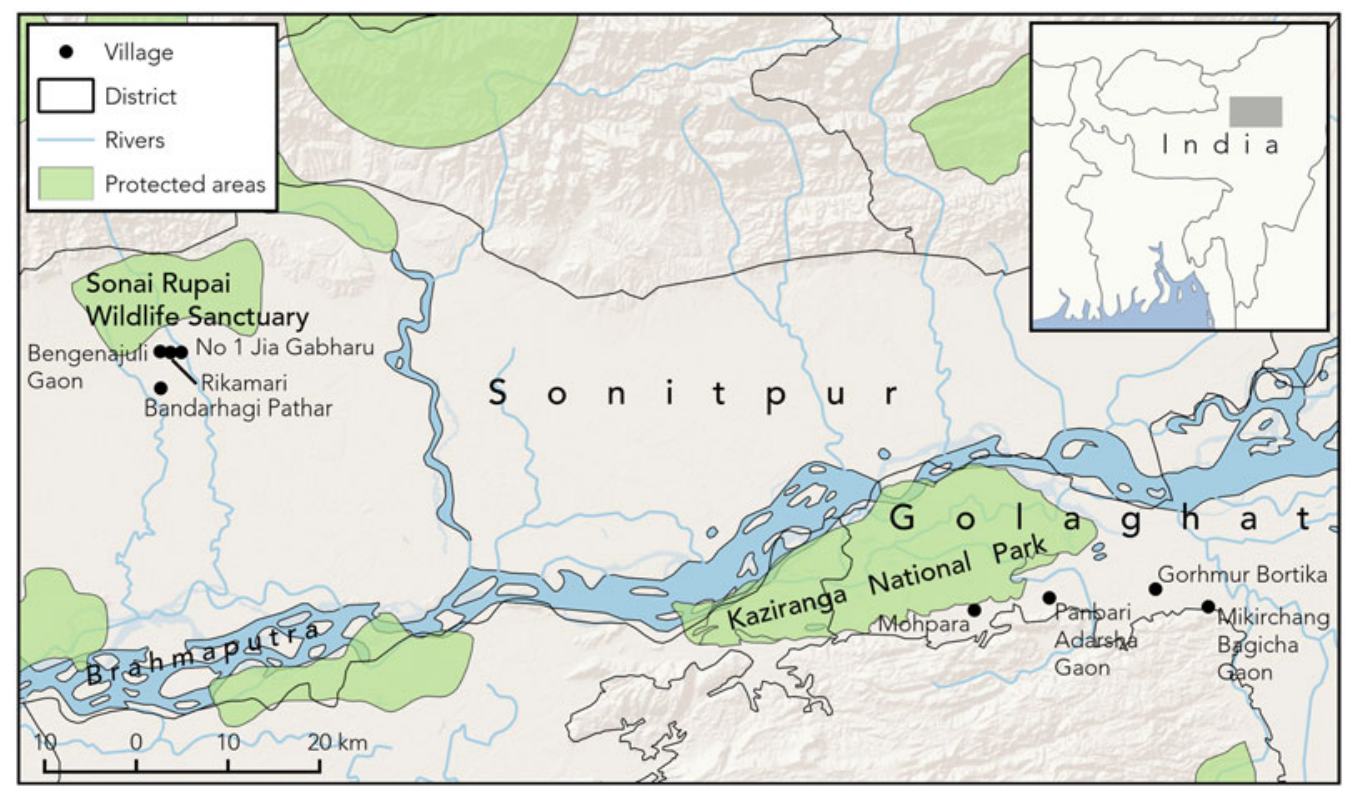

FIg. 1 The location of Sonai Rupai Wildlife Sanctuary, Kaziranga National Park and the eight study villages in Golaghat and Sonitpur districts of Assam, India.

emotional burdens; they share his tasks; and they provide him with extra supplies of money, materials, tools, skills, and cognitive guidance to improve his handling of his situation' (Caplan, 1974, p. 6).

In the study villages, coping was observed to start with the most fundamental unit in the natural support system: the family. The family collectively shares the anguish of losing a patch of ripe crops, a house or even a family member in an elephant attack, and the additional work or responsibility that ensues. Family support was evident in the case of participant $\mathrm{P}_{14}$ (Gorhmur village), whose house was destroyed by an elephant in the night. During the 2 days following the incident her husband, daughter, son and nephew helped her to clear up the mess and restore order. At another level the family was also found to help individual members to regain balance in their lives and achieve personal growth and development. For instance, P22 (Mikirchang village), whose husband was killed by an elephant, had been sleeping at the home of her in-laws since her husband's death because she was scared to remain alone in her hut. Her husband's family helped her cope with her loss by offering a place in their home and making her feel secure and sheltered.

Another unit in the natural support system that was found to aid people affected by wild elephants was the neighbourhood or community. All the study participants who guarded their fields at night said they always guarded in groups. Men from the neighbourhood, or those who have adjoining plots of land, get together in small groups and keep watch in the tangis (bamboo watch tower) at night, and participants were unanimous in the opinion that chasing elephants alone is impossible and fraught with risk. Whether in the fields or at home, people always seek the help of neighbours to chase away raiding elephants, and warn one another if elephants are in the vicinity. Communities rally to offer support at times of crisis, for instance, when somebody's house is damaged, or somebody is injured or killed by an elephant. Participant P19 (Gorhmur village), whose house was damaged by elephants, was saved from paying for the labour to rebuild his house because his neighbours carried out the work free of charge. Similarly, when P22's husband was killed it was the men from the village who called the police, took the body for post-mortem, made arrangements for the cremation, informed the forest officials, and helped her with the paper work.

Strong social ties can aid in reducing emotional distress in communities affected by marauding elephants; however, conversely, strained or acrimonious social relations can impede coping. This was evident in the narratives of $\mathrm{P} 16$ and $\mathrm{P}_{17}$ from Gorhmur village, whose families had been rehomed in Gorhmur after their ancestral village was washed away by a landslide. Both stated that resettled families were treated with hostility by the rest of the community and received no help when elephants entered their locality.

\section{Religion}

All the respondents in Golaghat and the majority $(n=36)$ in Sonitpur were Hindus, and the belief that elephants are living forms of the Hindu deity Lord Ganesha was popular, regardless of religious orientation or faith. In their narratives people often used reverential terms such as Baba, Tera and Teun (loosely translated as $\mathrm{He}$ with a capital $\mathrm{H}$, as in God) when referring to elephants, and used adjectives such as 
wise, sagacious, omniscient and omnipotent to describe elephants and their godly values.

Most study participants $(n=56)$ indicated they were willing to lose a certain amount of their crops in elephant raids each year, regarding it as an offering to God rather than a loss. Given that more than half of the participants $(n=43)$ earned $<$ INR 50,000 (c. USD 775) per year, this tolerance of crop loss to wild elephants is an indication of people's reverence towards these animals. Assamese Hindu participants $(\mathrm{n}=30)$ said that they invoked the elephant God every year in a ceremony called Dangoria Hokam, observed before the start of cultivation, pledging a portion of their produce in return for the safeguarding of their crops. Apart from this ceremony, which is performed mostly by individual households, people in all four study villages in Golaghat district and in Bandarhagi Pathar and Bengenajuli villages in Sonitpur district contribute cash or other offerings and collectively organize a Ganesh puja (prayer meeting) in August or September. Myths and superstitions are also part of the religious belief involving elephants, and this was also reflected in people's narratives. A septuagenarian participant (P68) from Bandarhagi Pathar narrated an incident that illustrates his belief in the divinity of elephants:

Elephants are God. They will never harm anyone without reason. An incident happened with me and to date it continues to awe me. It was no less than a miracle. It happened at a time when I was young and the elephant problem was not as severe as it is today. On that day I had reaped a patch of my field, and as it was late I left the harvested bundles in the field, thinking that I would collect them the next day. Next morning when I reached the fields I saw that elephants had visited my field at night and eaten some of the harvested bundles of crop that I had left the last evening. I was deeply saddened; I sat there and kept saying out loud to myself, 'Ganesh Baba why did you do this? I have never harmed you or abused you, yet why do you make me suffer thus?' Overcome with grief I came back home and did not go back that day. Next morning when I reached my field I was surprised to see that some new sheaves of ripe paddy were lying there in my field. I was surprised. I did not know where it came from but realized that since I had not done any evil deed, the elephant God had decided to return my crop to me. From that day onwards, even if elephants ruined my crops, I have never applied for compensation. I believe that what God has taken, He will return. Similar incidents have happened to other people. People who have prayed honestly have been blessed by Him.

Participants tolerated destruction caused by elephants, believing it to be punishment for their irreverence and failure to propitiate the Almighty, as illustrated by this excerpt from the interview of participant $\mathrm{P}_{23}$ from Mikirchang village:

There used to be an old man in our village who was a very devout man and did a lot of praying and Puja. Every morning he used to bathe in the river and go into the forest, where he had made a small clearing, and every day he offered flowers and incense at this place and prayed. It was a daily ritual, which he did without fail. When he was doing this, the village had no problems with elephants. But this man died some 9-10 years back. On his death bed he had requested people to continue with the tradition. But after his death, people forgot about this place and the praying stopped. I reckon it was around this time that elephants started troubling us. Now, we have started doing a Ganesh Puja every year, in which the entire village participates. Since the organization of this Puja the elephant problem has been less severe.
According to interview participants $(n=76)$, elephants as forms of God are bestowed with the power of omniscience and can hear if anybody uses foul or abusive language against them. One such incident was narrated by participant $\mathrm{P}_{74}$ from Bengenajuli village:

They [elephants] know what you are thinking. I have experienced it myself. Last year I had planted pumpkins in my backyard. The pumpkins had grown beautifully and were ripening. It was around this time that elephants attacked my garden. For 2 consecutive nights the elephants came and ate my pumpkins. On the third night I decided to stand guard and scare them away so that they would not come again. I waited in the outhouse for the elephants but that night they never came. The following night the same thing happened. On the third night of my watch, one elephant came and surprisingly, instead of eating the pumpkins, he headed straight towards the outhouse and banged against the concrete wall and broke it down. After that the elephant calmly entered the garden, munched a few pumpkins and left. I was really shaken after that and believe that they can really read your mind. It was like the elephant warned me that he knows what I am up to. Since then I have never attempted any such thing nor have I thought again of harming elephants.

\section{Anthropomorphism}

Anthropomorphism generally means the attribution of human qualities to non-human agents, be they animals, God, machines or natural phenomena. These humanlike characteristics may include physical appearance (e.g. Mickey Mouse), emotional states perceived to be uniquely human (e.g. pensive weather), or inner mental states and motivations (e.g. an uncooperative computer; Epley et al., 2007).

Study participants described elephants as gentle, wise, considerate and intelligent, reiterating that crop-raiding by elephants is not whimsical or predatory but arises out of their need to survive. Participants frequently mentioned that elephants were coming to the villages because their homes had been destroyed and people were occupying their space, and that elephants' crop-raiding activity was driven by hunger. Participants also equated elephants' right to life with that of people, a privilege not frequently accorded to other species.

Not only positive human qualities were attributed to elephants. Their notoriousness was also mentioned. Participant $\mathrm{P}_{1}$ said that elephants were 'like thieves, stealthy and cunning,' and participant P26 described how an elephant could evade chase by turning his back to the torchlights and 'pretending' to be hurt. Participant P12 also described the adoption of human tactics by elephants:

There were two elephants in this area and one was diseased. These two worked as a team and raided together. When they would attack a house, one of them would go and start attacking from the back while the other would stand guard at the entrance so that if any of the family members tried to escape from the front he could get hold of them and kill them.

Participants also described elephants as stubborn, vindictive, playful and calculating, thus assigning human characteristics to these wild animals. Participants also referred to 
the social life of elephants, and described enjoying the sight of 'mothers protectively guiding babies to the centre of the group', 'mothers walking with their children ensconced between their front legs' and a 'mother carefully carrying her infant over a wide ditch with her trunk like a human hand'. An incident in which an 'agitated mother' was unwilling to leave her 'poor baby' who had fallen into a trench was recounted remorsefully.

\section{Discussion}

People use a combination of problem- and emotion-focused strategies to cope with damage caused by wildlife, operating on a continuum between individual and social coping mechanisms (Treves et al., 2006). In the study villages, intrafamilial and intra-community relations of co-dependence, sharing and unity have helped individuals and families affected by wildlife-caused damage to cope with their emotional burden, offered psychological and material support, and engendered tolerance towards elephants. A system of mutual support has helped people to persevere in the worst of circumstances and given them hope in the face of adversity. By considering elephants as a form of God or God itself, people are able to tolerate the losses incurred. Affected individuals and families have their own personal tales through which they assign religious mystical values to distressing episodes that are beyond their control. This element of supernaturalism helps victims to endure losses and even regard these positively. Gradually these stories of divine intervention spread by word of mouth and become part of the collective memory of the community, reaffirming people's belief that elephants are agents of God (Moore, 2009). The belief that elephants are wise, godly beasts that do no harm unless provoked assuages feelings of anger and vehemence towards the animals and helps people to cope with losses (Sukumar, 2003). Elsewhere, other species are also tolerated on account of religious-cultural considerations; for example, baboons Papio spp. in South Africa (Kansky et al., 2016), lions Panthera leo in Ethiopia (Gebresenbet et al., 2017) and snow leopards Panthera uncia in Nepal (Ale et al., 2007).

In the study villages, anthropomorphism is also used as a coping strategy. In many non-Western cultures, anthropomorphism has long been practised in the form of animistic or totemic beliefs (Root-Bernstein et al., 2013); however, in the study area the tendency to anthropomorphize was associated more with seeking perceived bonds of mutualism with wildlife (Manfredo, 2008), and the need to interact effectively with non-human agents (Epley et al., 2007, 2008). By anthropomorphizing elephants as beings with needs similar to their own, people develop a sense of companionship and empathy with elephants that tempers their animosity towards the animals for the losses they cause. Empathy may also be a basis for anthropomorphizing, facilitating people's understanding of non-human species; for example, the belief that elephants are increasingly entering villages because forests are being destroyed absolves the elephants of any wrongful intentions and regards them as victims and co-sufferers.

By viewing the actions of elephants through the prism of human actions and emotions, people can predict and understand the behaviour of elephants better. This offers them a sense of certainty, which in turn reduces their anxiety over having to deal with something that is unknown and unfamiliar. Anthropomorphism is also a means by which people can regard elephants as intelligent beings that can reciprocate feelings of love and care, and not cause harm to those who have been kind to them.

The findings indicate that with effective emotion-focused coping strategies people can control the negative feelings and stress associated with negative encounters with wildlife. This may have wider implications for building tolerance and generating positive attitudes towards wildlife, improving the mental well-being of affected communities, and achieving conservation goals. However, previous studies of people's tolerance towards wildlife have focused primarily on attitudinal factors, access to land or capital, size of species, or compensation, and there has been little attention given to coping. Research on coping holds promise because coping based on social capital may facilitate coordination and cooperation among affected families for mutually beneficial collective action towards mitigation. Understanding psychosocial ways of coping could also help in finding practical ways to deal with adverse encounters between people and wildlife (e.g. through supporting/revitalizing natural support systems, respecting cultural and religious beliefs, and incorporating these with scientific knowledge in designing mitigation strategies).

Moreover, although the role of religious and cultural beliefs in nature conservation has been well studied (Gadgil et al., 1993; Hongmao et al., 2002; Fauna \& Flora International, 2013), the focus has been to regard these as allies in conservation, and the role of religion as a coping strategy in dealing with environmental stress has not yet been explored fully. An understanding of the effectiveness of religion in easing the emotional burden associated with stressful environmental events such as human-wildlife encounters could facilitate understanding of people's attitudes towards nature conservation. In the context of human-wildlife encounters particularly, this understanding, when integrated with mitigation initiatives, could help garner greater local support for conservation and ensure better outcomes.

\section{Acknowledgements}

I thank Martin Fisher for his helpful comments and suggestions, and for his assistance in preparing the map of the 
study area. I also thank the study participants for their time and inputs.

\section{References}

Ale, S., Yonzon, P. \& Thapa, K. (2007) Recovery of snow leopard Uncia uncia in Sagarmatha (Mount Everest) National Park, Nepal. Oryx, 41, 89-92.

Archabald, K. \& Naughton-Treves, L. (2001) Tourism revenue-sharing around national parks in Western Uganda: early efforts to identify and reward local communities. Environmental Conservation, 28, 135-149.

Caplan, G. (1974) Support Systems and Community Mental Health. Behavioral Publications, New York, USA.

Carver, C.S., Scheier, M.F. \& Weintraub, J.K. (1989) Assessing coping strategies: a theoretically based approach. Journal of Personality and Social Psychology, 56, 267-283.

Davies, T.E., Wilson, S., Hazarika, N., Chakrabarty, J., Das, D., Hodgson, D.J. \& Zimmermann, A. (2011) Effectiveness of intervention methods against crop-raiding elephants. Conservation Letters, 4, 346-354.

Decker, D.J. \& Chase, L.C. (1997) Human dimensions of living with wildlife: a management challenge for the 21st century. Wildlife Society Bulletin, 25, 788-795.

Decker, D.J. \& Lipscomb, J. (1991) Toward an organizational philosophy about integrating biological and human dimensions in management. Human Dimensions Perspectives, an occasional paper series of the Colorado Division of Wildlife, Denver, USA.

Epley, N., Waytz, A., Akalis, S. \& Cacioppo, J.T. (2008) When we need a human: motivational determinants of anthropomorphism. Social Cognition, 26, 143-155.

Epley, N., Waytz, A. \& Cacioppo, J.T. (2007) On seeing human: a three-factor theory of anthropomorphism. Psychological Review, 114 $864-886$.

Fauna \& Flora International (2013) Batwa Cultural Values in Bwindi Impenetrable and Mgahinga Gorilla National Parks, Uganda: A Report of a Cultural Assessment. Fauna \& Flora International, Cambridge, UK.

Fisher, M. (2016) Whose conflict is it anyway? Mobilizing research to save lives. Oryx, 50, 377-378.

Folkman, S. \& LAZARUS, R.S. (1980) An analysis of coping in a middle-aged community sample. Journal of Health and Social Behavior, 21, 219-239.

Fraser, H. (2004) Doing narrative research: analysing personal stories line by line. Qualitative Social Work, 3, 179-201.

GADGiL, M., BERKES, F. \& FolKe, C. (1993) Indigenous knowledge for biodiversity conservation. Ambio, 22, 151-156.

Gebresenbet, F., Baraki, B., Yirga, G., Sillero-Zubiri, C. \& BAuer, H. (2017) A culture of tolerance: coexisting with large carnivores in the Kafa Highlands, Ethiopia. Oryx, https://doi.org/10. 1017/So030605316001356.

Hill, C.M. (2004) Farmers' perspectives of conflict at the wildlifeagriculture boundary: some lessons learned from African subsistence farmers. Human Dimensions of Wildlife, 9, 279-286.

Hill, C.M. \& Wallace, G.E. (2012) Crop protection and conflict mitigation: reducing the costs of living alongside non-human primates. Biodiversity and Conservation, 21, 2569-2587.

Hirsch, B.J. (1980) Natural support systems and coping with major life changes. American Journal of Community Psychology, 8, 159-172.

Hongmao, L., Zaifu, X., Youkai, X. \& Jinxiu, W. (2002) Practice of conserving plant diversity through traditional beliefs: a case study in
Xishuangbanna, southwest China. Biodiversity and Conservation, 11, 705-713.

Kansky, R., Kidd, M. \& Knight, A.T. (2016). A wildlife tolerance model and case study for understanding human wildlife conflicts. Biological Conservation, 201, 137-145.

Kvale, S. (2007) Doing interviews. In The SAGE Qualitative Research Kit (ed. U. Flick), pp. 1-157. SAGE Publications, London, UK.

Lazarus, R.S. (1966) Psychological Stress and the Coping Process. McGraw-Hill, New York, USA.

Lazarus, R.S. \& Folkman, S. (1984) Stress, Appraisal, and Coping. Springer, New York, USA.

LyON, B.L. (2000) Stress, coping, and health: a conceptual overview. In Handbook of Stress, Coping, and Health: Implications for Nursing Research, Theory and Practice (ed. V.H. Rice), pp. 2-21. SAGE Publications, Thousand Oaks, USA.

MANFREDO, M.J. (2008) Integrating concepts: demonstration of a multilevel model for exploring the rise of mutualism value orientations in post-industrial society. In Who Cares About Wildlife? Social Science Concepts for Exploring Human-Wildlife Relationships and Conservation Issues, pp. 191-217. Springer, New York, USA.

Moore, L. (2009) Beware the Elephant in the Bush: myths, memory and indigenous traditional knowledge in north-eastern Namibia. Cultural Geographies, 16, 329-349.

Naughton, L., Rose, R. \& Treves, A. (1999) The Social Dimensions of Human-Elephant Conflict in Africa: A Literature Review and Case Studies from Uganda and Cameroon. A report to the African Elephant Specialist, Human-Elephant Conflict Task Force, IUCN, Gland, Switzerland.

Nyerges, A.E. (1992) The ecology of wealth-in-people: agriculture, settlement, and society on the perpetual frontier. American Anthropologist, 94, 860-881.

Osei-Owusu, Y. \& BAKker, L. (eds) (2008) Human-Wildlife Conflict: Elephant Technical Manual. FAO, Rome, Italy. Http://www.fao.org/ docrep/o1o/ai576e/ai576eoo.htm [accessed 14 August 2017].

Poland, B.D. (1995) Transcription quality as an aspect of rigor in qualitative research. Qualitative Inquiry, 1, 290-310.

Redpath, S.M., Bhatia, S. \& Young, J. (2015) Tilting at wildlife: reconsidering human-wildlife conflict. Oryx, 49, 222-225.

Root-Bernstein, M., Douglas, L., Smith, A. \& Veríssimo, D. (2013) Anthropomorphized species as tools for conservation: utility beyond prosocial, intelligent and suffering species. Biodiversity and Conservation, 22, 1577-1589.

Sukumar, R. (2003) The Living Elephants: Evolutionary Ecology, Behavior, and Conservation. Oxford University Press, New York, USA.

Teddlie, C. \& Tashakkori, A. (2003) Major issues and controversies in the use of mixed methods in the social and behavioral sciences. In Handbook of Mixed Methods in Social \& Behavioral Research (eds A. Tashakkori \& C. Teddlie), pp. 3-50. SAGE Publications, Thousand Oaks, USA.

Treves, A., Wallace, R.B., Naughton-Treves, L. \& Morales, A. (2006) Co-managing human-wildlife conflicts: a review. Human Dimensions of Wildlife, 11, 383-396.

\section{Biographical sketch}

MAYURI GoGor teaches social work at the University of Delhi, India and has a keen interest in the social dimensions of the human-nature interface. She conducts interdisciplinary research to address important issues related to conservation, livelihoods and the well-being of both people and wildlife. 